\title{
Luha ng Buwaya: Wika at isyung sosyo-politikal ng mga magsasaka
}

Alvarado, Elsie $\triangle$

Cebu Normal University, Philippines(elz_alvarado@yahoo.com)

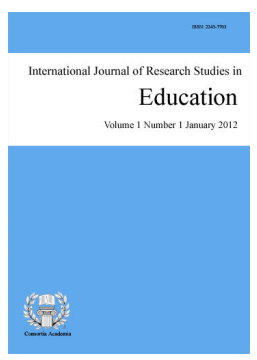

Accepted: 29 May 2019 Online ISSN: $2243-7711$

OPEN ACCESS

\section{Abstract}

This study aims to reveal the literary devices and socio-political issues experienced by the workers in the novel Luha ng Buwaya of Amado V. Hernandez. It specifically answers three aspects; figures of speech, social issues and political issues. The study anchored to Mimetic theory by Aristotle. Qualitative method was used through discourse analysis in order to analyze the dialogues of the workers as the main character of the novel. The findings of the study shows that the figures of speech used in the novel are simile, metaphor, hyperbole and rhetorical question so that workers could express freely their heartaches and distress violated as farmers. The social issues found in the novel are violations to human rights as workers such as no freedom of expression, the right to own a home, inequality of sharing of the product as owner and worker of the farm. Whereas the political issues enclosed the inequality views of the society to the poor and rich people, the court favored the owner of the farm and the rich bought the law. Based on the findings of the study, it has been proven that the farmers use figures of speech due to hardships and distress experiences from the society and felt dismay due to the violation of the human rights as farmers. The study recommends that the life of the writer will also be analyzed in order to further understand the novel.

Keywords: literary devices; socio-political issues; language; human rights; farmers 


\section{Luha ng Buwaya: Wika at isyung sosyo-politikal ng mga magsasaka}

\section{Introduksyon}

Larawan ng pang-aabuso sa mga magsasaka ang sinisigaw ng isang panitikan. Ayon kay Salazar et al. (1995), ang panitikan ay siyang lakas na nagpapakilos sa alinmang uri ng lipunan. Dagdag pa niya, ang tunay na kahulugan ng panitikan ay nakikita sa mga katotohanang ito tungkol sa mga ideya, isipan, at damdamin ng tao gaya ng pag-ibig, katungkulan, kaligayahan, panibugho, galit, pagkahabag, pag-alipusta, paghiiganti at iba pa. Nang dahil dito nagagawang tahakin ng manunulat ang pinakailalim na damdamin ng bawat mambabasa na siyang humuhubog sa pagkatao nito. Malikot ang paglalakbay-diwa ng isang manunulat dahil naipipinta niya ang lahat ng bagay na nakakapaligid sa kanya. Sadyang malaki ang nagagawa ng panitikan sa larangan ng pasulat at pasulat ng isang tao dahil dito nalalaman niya kung papaano makihalubilo sa kapwa na walang pga-aalinlangan. At higit sa lahat, nasungkit ng mambabasa ang pinamagandang kagandahang-asal na makukuha sa akdang pampanitikang nabasa.

Panitikan ang tawag sa lahat ng uri ng pahayag - nakasulat man ito, binibigkas o kahit ipinapahiwatig lang ng kilos ngunit may takdang anyo o porma katulad ng isang nobela (Santiago, 2007). Ang nobela ay isang uri ng akdang pampanitikan na binubuo ng tagpi-tagping tagpo ng pangunahing tauhan. Ito ay isang mahabang salaysay na nahahati sa mga kabanata. Sa bawat pagsisimula at pagtatapos ng kabanata ay bumabangon mula sa pagkadapa at nagpapatuloy sa pagharap ng bukas. Ito ay nagsasalamin ng iba't ibang tagpuan kung saan nakikipagsapalaran ang pangunahing tauhan sa mga suliraning kinakaharap niya sa buhay. Saad naman ni Arrogante et al. (1983), ito y isang kawil ng kawili-wiling pangyayari na pinaghahabi-habi sa isang mahusay na pagbabalangkas. Naging malaya at malawak ang paglalakbay-diwa ng mambabasa dahil magagawa niyang umiyak at matuwa habang nagbabasa o sa medaling sabi, napukaw ang kanyang natutulog na damdamin. Masarap namnamin nang dahil sa nabasa, nakuhang baguhin ang sariling pananaw bilang bunga sa lahat ng kanyang natutunan. Naihahambing din ang sarili sa tauhan at naitutuwid ang sarili sa pagkalihis ng landas.

Winika ni Reyes (1982), ang nobela ay kinalalarawan ng sariling pag-uugali, mga kilos, at damdaming katutubo ng baying pinaghanguan ng matiyagang sumulat, at hindi lamang ganyan kung hindi gumagamot din naman sa maraming sakit sa pag-uugali, maling paniniwala at masasagwang kilos na nagpupusyaw sa dapat na magningning na kapurihan ng tao kung kaya nabubuhay. May matinding mithiin ang makata sa paglikha ng obra-maestra na tunay na nagsasalamin sa kanyang buhay at hindi malayong mangyayari sa lahat ng tao. Naglalayong maikintal sa mga puso at isipan ang kagandahan ng buhay sa pamamagitan ng paghahatid ng samutsaring kathang-isip na punong-puno ng aral. Gayon pa man, hindi na masyadong napapahalagahan ang nobela dahil maraming kabataan ngayon ang mahilig sa biswal, mas nanaisin pang manood ng pelikula, telebisyon at iba pang kagamiting teknolohiya na ginagamit sa medaling paraan. Ang mga mag-aaral ay kakaonti na lamang ang pumupunta sa silid-aralan upang magbasa ng mga aklat lalo na ang nobela. Dinadaanan na lamang sa mga mata dahil masyadong makapal at nakakabagot itong basahin.

Lubhang napakalaking pangangailangan ang pagtugon sa pagbibigay buhay sa mga kuwento ng buhay na tanging ang panitikan lamang ang makapagsalaysay. Nararapat basahin lalo na ang nobelang Pilipino alang-alang sa kanilang panlipunan at kasaysayang kahalagahan na naihatid sa nakakarami. Ngunit ayon kay Yu (2006), iilan lamang ang nagsusuri sa nobela at kung mayroon mang pag-aaral ng mga particular na manunulat na karamihan ay gumagamit ng historikal at sosyolohikal na pananaw. Subalit karaniwang masinop ang pagtalakay sa mga pormal na katangian ng sining o ng ugnayan ng manunulat sa kasaysayan sapagkat higit na pinahahalagahan ang mga datos na bumubuo sa talambuhay ng may-akda sa halip na pagtuunang-pansin ang politikal, estetiko at ideolohikal na aspeto.

Dahil dito, nahimok at nahamon ang mananaliksik nap ag-aralan at siyasatin ang lunas ng suliraning ito. 
Ang pagkakaroon ng bukas na isip at malawakang pananaw ay siyang nagpapatibay sa sarili na buklatin at buhayin ang kaban ng nobela, yaong may pagmamahal at pagmamalasakit sa kapanganakan ng lahat. Nagmumula sa totoo at dalisay na karanasan na humuhubog sa pagkatao ng bawat nilikha. Naghahatid ng pagkilos at paggalaw ng lipunan na akma sa panlasa ng mambabasa katulad ng nobela ni Amado V. Hernandez, Ang Luha ng Buwaya. Ang likhang ito ay pinaparangalan bilang "for Excellence in Pilipino Writing" sa National Press Club-Esso Silangan Journalism Contest.

Ang Luha ng Buwaya ay nagpapamalas ng mga katunayan sa buahay: kahirapan, kawalan ng katarungan at kaapihan laban sa mayayaman. Subalit ipinapakita rito ang pagkakais at pagtitiwala sa kapwa upang makamit ang adhikain ng isang indibidwal. Ginagamit ang utak para masungkit ang magandang kapasyahan at puso naman para makaramdam sa mga hinaing ng kapwa manggagawa na nagdadala sa pagtutulungan. Pinatunayan sa nobelang ito na ang pagtatanim ng magandang butil ay magbubunga ng mas marami pang magaganda at masasarap na kaligayahan, hindi lamang sa isa kundi sa nakakarami. Iyan ang kagandahang-asal na natatamo sa nobelang ito. Tunay ngang kapupulutan ng maraming magagandang kilos at gawi ang Luha ng Buwaya subalit sa likod nito ay may nakatagong mas matinding layunin ang makita. Napapalooban ng mga suliraning panlipunan na masasabing nangyayari talaga sa pang-araw-araw na pamumuhay ng tao. Katulad na lamang ng pagkamatay ng kapamily dahil walang perang pambili ng gamot, pinagkaitan ng edukasyon, pagtatrabaho nang sobra-sobra, pagkatanggal sa trabaho na walang sapat na dahilan, pagkakulong na hindi pinakinggan ang panig ng nasasakdal at marami pang iba na sadyang nagbibigay nang matinding sakit at poot sa puso sa mga bumabasa ng likhang sining ni Ka Amado.

Napakalungkot ng senaryong nabanggit ngunit ito ay suliraning parang linta na sumasakop sa utak ng bawat isa. Kinakailangan na magkaroon ng pagbabagong pananaw ang bawat Pilipino para sa ikauunlad ng lahat. Naghahangad na ang pag-aaral sa nobela ni Amado V. Hernandez ay mamulat, magbago ng prinsipyo at gagawin nang tama ang tungkulin ng mga tagapamahala ng gobyerno, mamamayan at higit sa lahat ang mga mag-aaral na maging positibo sa pananaw upang magkaroon nang matiwasay at masaganang buhay ngayon at sa hinaharap.

Kung kaya, ninanais ng pag-aaral na bigyang-puwang sa puso ng mga mambabasa ang pagbabasa at pagpapahalaga sa mga nobelang naglalayon ng pagbabago sa lipunan at higit sa lahat mabigyang-pugay ang manunulat na si Ka Amado sa kanyang kabayanihan sa larangan ng panitikan. Nilalayon ng pag-aaral na ang mga Pilipino ay mamulat sa katotohanan, mapahalagahan ang nobela sa buhay, maunawaan ang kaugnayan ng makata sa akda, labanan ang kahirapan, at pang-aapi ng kapwa. Nagsisilbing behikulo ito sa mga mambabasa na pagyamanin ang mga nobelang Pilipino, mahalin ang sarili, ang kapwa at maging ang bayan tungo sa kaunlaran ng nakakarami.

Nakaangkla ang pag-aaral sa teoryang Mimetiko ni Plato. Ang teoriyang mimetiko ay pagsusuri sa simbolong napapaloob sa akda ng iba't ibang akdang pampanitikan. Isa ring pagsisiyasat na ang panitikan ay kamukha ng buhay. Sa teoriyang ito nailalahad ang mga pangyayaring tunay na nagaganap sa lipunan.

Ayon kay Plato, ang teoriyang ito ay tunay na alagad ng sining na nagibibigay ng inspirasyon sa bawat mambabasa. Ang manunulat ay itinuturing na paksa o pinapaksa sa sulatin kaya sapat na itong katibayan na nagsasabing siyang katotohanan. Ang teoriya ring ito ay maiuugnay sa mga dulog ng pampanitikan na sosyolohiial/marxista at moralistiko. Ang sosyolohikal/marxista ay hinahanay sa panitikan ang mga realidad ng lipunan, ang patuloy na pakikitunggali ng nagtatalong klaseng sosyal, ekonomikal, politikal, kultural, institusyonal, at iba pang puwersa sa lipunan. Ipinapakita na laging may pakikibaka ang panitikan. Ang moralistiko naman ay nakasentro sa bisa ng panitikan sa kaasalan, kaisipan, at damdamin ng tao. Binanggit ni Buensuceso et al. (1997), ang panitikan ay may tungkuling itaas ang ating pagpapasya o panlasa upang makaabot sa kinikilalang matapat at tumpak sa tunay na buhay. Nangangahulugang ang teoriyang mimetiko ay naghahatid ng katunayan sa buhay. Sa pamamagitan ng teoriyang ito ay naihahambing ang katotohanan o realidad na nangyayari sa lipunan na makikita sa nobelang Luha ng Buwaya. Inilalahad ang mga sagisag at paglalarawan sa mga katunayan na ginagamit sa mga puwersa ng lipunan katulad ng lugar, tauhan at pangyayaring may kapilas 
Alvarado, E.

ng buhay ng tao. Ang mga pangyayaring ito ay binibigyang buhay sa pamamagitan ng pag-uugnay-ugnay ng mga detalye mula sa simula hanggang katapusan.

\subsection{Layunin ng pag-aaral}

Ang pananaliksik na ito ay naglalayong masuri ang wika at isyung sosyo-politikal na nakapaloob sa nobelang Luha ng Buwaya ni Amado V. Hernandez. Tinitiyak na masagot ang tatlong aspekto; matatalinghagang pahayag, isyung panlipunan at isyung pampolitikal. Nais mabunyag ng pag-aaral na hitik sa katarungan ang mga manggagawa na inilalarawan sa nobelang Luha ng Buwaya ni Ka Amado.

\section{Disenyo ng pag-aaral at pamamaraan}

Kwalitatibong pamamaraan ang ginamit sa pag-aaral upang masuri ang nilalaman na inilalarawan sa nobela. Kinakasangkapan ang diskursong pagsusuri para matukoy ang mga pangyayari sa nobela na nagbubunyag ng wika ng manggagawa at pang-aabuso laban sa mga manggagawa. Ang pinagmulan ng datos ay nobelang Luha ng Buwaya ni Amado V. Hernandez. Isa-isang siniyasat at sinuri ang malalim na kahulugan ng akda na nagsasalamin ng wikang ginamit ng mga manggagawa at kaapihang nararanasan dulot ng lipunan. Sinuri ang akda sa pamamagitan ng pagsipi sa mga pangyayaring napapalooban ng mga pananalitang naging sandata sa pakikipaglaban ng pangunahing tauhan sa kontrabida. Sinipat din ang mga pangyayaring naglalarawan ng hitik sa katarungan na gawa ng tao at lipunan at maging pagpanig sa mayaman ng batas.

\section{Mga resulta at pagtalakay}

Batay sa masusing pagsisiyasat, napatunayang ang nobelang Luha ng Buwaya ni Amado V. Hernandez ay gumamit ng matatalinghagang pahayag upang maipahayag ang mga saloobin ng mga mangsasaka laban sa may-ari ng lupa. Habang sinasalamin naman ang iba't ibang isyung panlipunan na naging sanhi ng pagdurusa ng mga magsasaka at lantarang naging kalaban ang namamahala sa batas upang kampihan ang maypera. Matutunghayan sa tulong mga talahanayan ang resulta ng pagsusuring ginawa.

\section{Talahanayan 1}

Matatalinghagang pahayag

\begin{tabular}{|c|c|c|}
\hline Mga Tayutay & Mga Pahayag & Kahulugan \\
\hline Pagtutulad & $\begin{array}{l}\text { "Tila napawi na ang guhit sa pagitan ng katandaan } \\
\text { at kabataan ng lalake at babae..." } \\
\text { "Parang mga mga tapon at palaboy, ang pagtitiis sa } \\
\text { mga taon ng pagsakop at liberasyon, at tulad ng } \\
\text { tubig sa isang basong Kristal..." }\end{array}$ & $\begin{array}{l}\text { Gumamit ng mga matatalinghagang pahayag ang } \\
\text { pananalita ng mga magsasaka lalo na ang } \\
\text { pangunahing tauhan na si Bandong sa tuwing } \\
\text { nagkakaroon ng pagtitipon o pagpupulong sa } \\
\text { kapwa magsasaka. }\end{array}$ \\
\hline Pagwawa-ngis & $\begin{array}{l}\text { "Baka aniko ito'y 'sang hakbang na palapit sa 'king } \\
\text { pangarap..." } \\
\text { "Ang magsasaka ay isang langgam at masunuring } \\
\text { kordero..." }\end{array}$ & $\begin{array}{l}\text { Lumabas sa bibig ni Bandong ang pagiging } \\
\text { madamdamin sa tuwing inaalipusta ng may-aring } \\
\text { lupa ang magsasaka. }\end{array}$ \\
\hline Pagmama-labis & $\begin{array}{l}\text { "nagbibilang ng sisiw" } \\
\text { "katarunga'y kakambal ng lupa, paglipad ng } \\
\text { pagong, lalo kang lumaki sa paningin at dalangin } \\
\text { ng aking kaluluwa..." } \\
\text { "Sa isang umiibig sa'yo nang 'sang siglo, sa isang } \\
\text { namamatay sa pagkainip, ang anim na buwan ay } \\
\text { anim na taon..." }\end{array}$ & $\begin{array}{l}\text { Ang paggamit ng pagmamalabis sa pananalita ay } \\
\text { bunga ng matinding pighati at galit ng mga } \\
\text { magsasaka sa nobela. }\end{array}$ \\
\hline Pagtata-nong & $\begin{array}{l}\text { "Kung hukuma'y di pa naming masabi ang lahat ng } \\
\text { dapat sabihin at iaing, sa'ng silong pa ng langit } \\
\text { maaaring dinggin ang katwiran ng mga api? } \\
\text { "Nasaan ang hustisya? }\end{array}$ & $\begin{array}{l}\text { Ang kawalan ng hustisya ang naging dahilan ng } \\
\text { paulit-ulit na pagtatanong ng mga magsasaka sa } \\
\text { batas. }\end{array}$ \\
\hline
\end{tabular}

Malinaw na ipinakita sa talahanayan 1 na gumamit ang mga magsasaka ng wika sa tulong tayutay at idyomatikong pahayag upang maipalabas ang saloobin at damdamin sa mang-aapi. Ginamit ang tayutay na pagtutulad, pagwawangis, pagmamalabis at pagtatanong upang hindi lantad na maiparating ang kanilang puot at 
Luha ng Buwaya: Wika at isyung sosyo-politikal ng mga magsasaka

hinagpis. Ang tayutay ay mga salita o pariralang ginagamit upang maging kaaya-aya ang pagpapahayag.

Ginamit ang pagtutulad na tayutay sa mga usaping naghahangad ng kasagutan. Ang pagtutulad ay ginagamitan ng mga pang-ugnay tulad ng tila, marail, parang, tulad ng at iba pang pang-ugnay na ginagamit sa paghahambing. Gaya ng "Tila napawi na ang guhit sa pagitan ng katandaan at kabataan ng lalake at babae..." na inilalarawan sa nobela ang lalake at babae noon na hindi na naiiba sa isip at gawi. Kapansin-pansin na iniuugnay ang katandaan at kabataan ng lalake at babae na hindi hadlang ang edad upang gumawa ng tama at maging mabuting hulwaran sa ibang tao. Nais rin ipabatid na kailangang magtulungan ang bawat isa babae man o lalake, matanda man o bata sa pakikipaglaban sa mang-aapi. Na kinakailangang manindigan at hindi matakot lumaban para sa makamtan ang minimithi sa buhay. Tunghayan ang pahayag na "Parang mga mga tapon at palaboy, ang pagtitiis sa mga taon ng pagsakop at liberasyon, at tulad ng tubig sa isang basong Kristal..." Nangangahulugang ang magsasaka ay itinuring na mga basurang itinapon at palaboy sa lansangan kung tratuhin ng mga may-ari ng lupa. Hindi nakaligtas sa lupang sinasaka dahil simula't sapol magsasaka pa rin ang hantong. Malilirip na ang maraming taon na ang nakalilipas sa pagtitiis ng mga magsasaka laban sa maylupa. Hayagang inihalintulad ang mga sarili sa isang tubig sa basong Kristal na malinis ngunit nakakulong at walang kalayaan. Nagkakaroon lamang ng kalayaan kung itapon ito sa lupa ngunit titilapon lamang ito kahit saan na hindi alam kung saan patungo. Isang katotohanang sa pagitan ng magsasaka at maylupa sa nobela na nakakulong pa rin ang magsasaka sa tinig ng may-ari ng lupa. Tikom ang bibig at walang kalayaan na makapagsalita kung kaya idinaan na lang nila ang pagpapahayag sa paghahambing upang maitago ang kanilang nais.

Pagwawangis naman ang ginamit ng mga magsasaka sa paghinga sa mga nararamdaman lalo na kung mayroong pagtitipon sa loob ng sakahan. Ang tayutay na ito ay tuwirang inilalarawan ang isang bagay. Katulad ng paghalintulad sa mga magsasaka sa langgam at masunuring kordero na ibig sabihin ay hindi makakalayo ang magsasaka sa lupang sinasaka dahil ito lang ang tanging ikinabubuhay. Tulad ng isang langgam na namamahay sa lupa at doon tinitipon ang mga pagkain. Ang langgam ay maituturing na pinakamababang uri ng hayop o insekto na hindi na nabubuhay kung walang lupa o bagay na puwedeng pagtaguan. Hindi ito nalalayo sa mga magsasaka dahil ang ikinabubuhay rin nito ay pagsasaka at kung walang sakahan ay tiyak hindi rin sila mabubuhay. Malungkot ang paghahambing na ito ngunit kung titingnan sa makabagong perspektiba ay may katotohanan dahil sa ngayon ang pagsasaka'y hitik sa karangyaan. Habang katulad din sa masunuring kordero ang magsasaka dahil sunud-sunuran lamang ito kung ano ang nais ng maylupa dahil kung hindi susunod ay tiyak na hindi ka na makapagsasaka.

Likas na sa Pilipino ang pagiging eksaherado sa pananalita lalo na kung may matinding damdamin sa isang bagay. Ang nobela ang gumamit ng pagmamalabis sa pagpapalabas ng damdamin gaya ng nagbibilang ng sisiw na ibig ipakahulugan nito ay pantay-pantay na paghati sa lupa ng pamahalaan ay gaya ng pagbibilang ng sisiw na hindi mawari kung kailan maisakatuparan. Kung katarungan naman sa pang-aapi ng maylupa laban sa mga magsasaka ay hindi pa rin maabot-abot.

Kitang-kita rin ang pagmamalabis ng pahayag sa linyang katarunga'y kakambal ng lupa, paglipad ng pagong, lalo kang lumaki sa paningin at dalangin ng aking kaluluwa...

Ginamit din ang pagmamalabis sa tinuran ni Bandong sa kanyang iniibig na kaytagal na nasungkit ang Oo dahil sa taglay na kulturang Pilipina. Masisilayan ito sa pahayag na Sa isang umiibig sa'yo nang 'sang siglo, sa isang namamatay sa pagkainip, ang anim na buwan ay anim na taon... Nagpapatunay ang linyang nabanggit na walang makapipigil sa pananalita sa isang taong umiibig. Hindi mapigilan ang bugso ng damdamin kung kaya'y talastas nito ay punong-puno ng talinghaga. Ang pahayag ding nabanggit ay sinabi ng pangunahing tauhan sa isang pagtitipon ng mga magsasaka na aabutin sila ng siglo sa pagkamit ng nais sa sakahan. Ang pakikibugno sa pantay-pantay na hati sa ani ng lupa ay matagal ng hinaing ng magsasaka na hindi kailanman natamo. Gayunpaman, hindi tumigil ang mga magsasaka sa pagpapahayagng kanilang saloobin sa pag-asang dumating din ang umaga sa kanilang nayon.

Matutunghayan sa talahanayan 1 ang mga binitawang salita ng pangunahing tauhan sa nobela na si Bandong. 
Alvarado, E.

Namumutawi ang pait at poot na nararamdaman ng puso na tanging kawalan ng hustisya ang may kagagawan. Gayunpaman, bunga ng pag-ibig ay nagkakaroon ng puwang sa kanyang puso ang saying dulot ni Pina. Makikita sa unang bahagi ng talahanayan na gumamit ng tayutay na pagwawangis ang tauhan sa pagsinta ng iniirog. Malinaw na kinakasangkapan ang wika upang maging kaaya-aya at makakuha ng interes sa mambabasa. Hayagan ding ginamit ang tayutay upang hindi tuwirang maipahayag ang tunay na damdamin ng tauhan na nagdudulot ng kariktan sa nobela.

Ang isang bagay ay maaaring mailalarawan sa tulong ng tayutay na tinatawag na pagtutulad. Kasasalaminan ng paghahalintulad ang wikang ginamit sa nobela. Ito ay nagsasaad ng pagpapalalim ng mensahe upang mag-isip at magsuri ang mambabasa. Malaki ang naitutulong ng tayutay na pagtutulad sa nobela upang magamit sa pasaring ng taong gumamit nito katulad ng tila napawi ang guhit ng katandaan sa pagitan ng lalake at babae na tinutukoy ang magsing-irog na sina Bandong at Pina. Sa tindi pa naman ng kanilang pagmamahalan ay hindi na kailangang sabihin kung ano ang uri ng kanilang pagtitinginan dahil sa tinginan pa lang ay sapat na ito.

Lumilitaw rin sa nobela ang tayutay na paglalamabis dulot ng lubhang emosyon at damdamin ng pangunahing tauhan. Ang taong nakaranas nang matinding pang-aapi ay hindi maiiwasang makapagpahayag ng labis na panibugho. Kagaya ng mga linyang, nagbibilang ka ng sisiw at isang umiibig sayo nang 'sang siglo, isang namamatay sa pagkainip, ang anim nan a buwan ay anim na taon na nagsasaad ng malayo sa katotohanan. Ibig sabihin ang pagmamalabis na tayutay ay ginamit sa nobela upang maipahayag ang matinding pag-ibig ni Bandong kay Pina. Sa ganitong sitwasyon, malinaw na nagpapakipot ang sinisinta bunga ng kultura ng Pilipino noon. Kailangang maghintay ng lalaki kung kailan siya sasagutin ng babae upang mapatunayan ang kanyang matinding pagmamahal.

Dulot ng maraming pang-aapi at kawalan ng katarungan sa nayon nina Bandong, ang manunulat ay gumamit ng wikang nauuwi sa kawalan. Ang tayutay na pagtatanong ay ginamit sa nobela sa tuwing nakaramdam nang matinding pagod laban sa hustisya. Halimbawa na lamang nito ang linyang binitiwan ni Bandong na "...kung ang hukuma'y di pa naming masabi ang lahat ng dapat sabihin at idaing, sa'ng silong pang langit maaaring dinggin $n g$ katwiran ng mga api? Nagbabadya nang sobrang pighati dulot ng kasakiman at ganid sa kapangyarihan. Ang lipunang ginagalawan ng tauhan sa nobela ay naghari ang kawalanghiyaan. Naghari ang inaapi laban sa mang-aapi na walang hukumang pumanig. Madalas itong nakikita sa tunay na buhay na hindi dininig ang katarungan sa mahihirap. Ganito ang naranasan ni Bandong sa kanyang lipunan. Kaya lagi niyang tanong ay “... Nasaan ang hustisya?” Mapapansin na hindi pantay ang hustisya sa kanilang nayon. Ang tanging dininid ay yaong may pera na kayang bilhin ang hustisya.

Samakatuwid, ang nobela ay gumamit ng matatalinghagang salita tulad ng pagtutulad, pagwawaangis, pagmamalabis at pagtatanong upang hindi lantad na malaman ng mang-aapi ang nais ng inaapi. Kinakasangkapan din ito upang magtaglay ng angking sining at kagandahan ang akda na siyang nakapaghihikayat sa mambabasa. Nang sa gayon din ay magkaroon ng interes ang mga mambabasa na ugkatin ang nakatagong layunin ng manunulat sa pagsulat ng akda. Naging likas at natural lamang ito sabawat paglalahad at pagsasalaysay ng mga pangyayari sa akda. Ito ang ginagamit na estilo ng may-akda upang maihayag ng pangunahing tauhan ang kanyang damdamin sa kanyang sinisintang dilag. Higit sa lahat, maisangguni at maipabatid niya ang kanyang karunungan sa iba lalo na sa mga magsasaka ay iskuwater. Samantalang sa mga magsasaka, malaking naitutulong ng mga tayutay upang hindi lantarang maipalabas ang kanilang mga hinaing laban sa pamahalaan at sa iba pang mang-aapi. Ang talahanayan 2 ay naglalahad ng mga pangyayaring panlipunan na hitik sa katarungan.

Namutawi ang suliranin sa kahirapan sa mga taga-Sampilong lalo na sa mga iskuwater at magsasaka. Tinataglay ang akdang sinisiyasat ang kawalan ng pagkain, hindi sapat ang kinikita sa pamliya, at hitik sa edukasyon ngunit sa kabila ng karukhaan, mayroon pa ring pilak at ginto na itinatalaga sa mahihirap. Ipinapakita rito na hindi sa lahat ng pagkakataon nagwawagi ang kahinaang dulot ng paghihirap bagkus, naging susi sa paglaban sa kahirapan. 
Talahanayan 2

Isyung Panlipunan

\begin{tabular}{lll}
\hline \multicolumn{1}{c}{$\begin{array}{c}\text { Mukha ng Buhay na } \\
\text { Sinasagisag }\end{array}$} & \multicolumn{1}{c}{ Mga Elemento ng Nobela } & \multicolumn{1}{c}{ Paglalarawan } \\
\hline Kahirapan & Tauhan & $\begin{array}{l}\text { Namatay ang asawa ni Hulyan dahil sa } \\
\text { walang perang pambili ng gamut at } \\
\text { pagpatingin sa doktor. }\end{array}$ \\
Pag-ibig & Tunggalian & $\begin{array}{l}\text { Hindi matangap ni Dislaw ang pagkabigo } \\
\text { sa pag-ibig kay Pina kaya may masamang } \\
\text { balak ito. }\end{array}$ \\
$\begin{array}{l}\text { Makapangyarihan ang } \\
\text { Mayaman }\end{array}$ & Tauhan at Tunggalian & $\begin{array}{l}\text { kaya hindi kailanman dumalo sa } \\
\text { pagsasakdal. }\end{array}$ \\
\hline
\end{tabular}

Ang tao ay nararapat na binibigyan ng karampatang karapatan na maitataguyod ang pamilya sa mga pangunahing pangangailangan sa buhay katuald ng pagkain, tirahan at edukasyon subalit sa nabanggit ay mistulang panaginip sa mga kasama (magsasaka) na isang kahig isang tuka dahil hindi binibigyan ng pantay na karapatan sa partehan ng saka. Matutunghayan ito sa mga pangyayari sa mga tauhan at pakikipagtunggali gaya ng pagkamatay ni Sepang na asawa ni Hulyan dulot ng kawalan ng salapi. Nagmamakaawa sa may-ari ng lupa na huwag munang kaltasan ang kanyang utang may pambili ng gamut ngunit parang bingi ang may-ari. Sa ganitong usapin, malinaw na nilabag ang Konstitusyon Artikulo II Sek.15 na, "The state shall protect and promote the right to health of the people and instill health consciousness among them." Ang batas na ito ay patunay na hindi nabibigyan ng sapat na pangangalaga ang mga tauhan sa nobela alinsunod sa umiiral na batas. Bagay na kahindik-hindik dahil nauuwi ito sa malaking kasawian ng buhay. Malinaw na hindi natam ang itinatadhana sa batas. Pinagtibay pa ito sa Sanctity of the Family as the Basic Social Unit ng Konstitusyon Artikulo II Sek.12 na, "The state recognizes the sanctity of family life and shall protect and strengthen the family as the basic autonomous social institution." Isang kamalayan na dapat mangingibabaw sa bawat miyembro ng lipunan, isa na rito ang pamilya. Dapat ipaglaban ng pamilya ang karapatang ito at huwag hayaang yurakan nang kung sino lang na bahagi pa rin ng lipunan.

Sa kabilang banda, bukod sa samutsaring suliraning kinakaharap ng mga tauhan sa nobela ay matindi rin ang pakikipagtunggali sa buhay pag-ibig. Isang katotohanan na kapag hindi ka gusto ng iyong iniibig ay hahamakin ang lahat kahit lulusong man sa putik o kasamaan. Kakikitaan ang isyung ito ng pagkamakasarili ng tao at hindi pagkamakatao upang masunod ang kagustuhan. Ang tunay na pag-ibig ay nakahandang maghintay ngunit sa paghihintay na ito ay mayroong mga taong hindi makatanggap ng pagkatalo sa pag-ibig. Katulad ng kasakiman ni Dislaw sa pag-ibig kay Pina. Ninanais niyang maangkin si Pina kahit paman humantong sa sukdulan. Ang matinding pagnanasa sa kagandahan ni Pina ay nag-uudyok kay Dislaw na gagawa ng masama gaya ng panggagahasa. Ang pag-ibig nina Pina at Bandong ay dumaan ng pagsubok na hatid ni Dislaw ngunit hindi nagtagumpay sa kanyang balak dahil naabutan ito ng Bandong. Ang ganitong senaryo ay tunay na nangyayari sa lipunan. Ang pagkamakasarili ng tao ay nagluluklok sa kanya na gawin ang masama. Ito ay isyung panlipunan na namayani na sa totoong buhay kahit saang bahagi ng Pilipinas.

Hindi maituturing na masaya ang taong nag-iibigan kung walang kalaban sa pag-ibig. Mayroong mga taong naiinggit kaya hindi masaya kung nakikita silang masaya. Kaya, gagawa at gagawa talaga ng kabulastugan upang maipakita ang kanyang kalakasan. Ito ang mga taong hindi kontento sa buhay at walang pagkasawa sa buhay na mayroon siya. Ang isyung panlipunan tungkol sa pag-ibig ay pilit na nilabanan nina Bandong at Pina dahil naniniwala ang isa't isa na makapaghihintay ang pag-ibig na wagas.

Sinasalamin ng lipunan ang pang-aapi ng mayayaman sa mahihirap gamit ang kanilang yaman. Ang tinig na kadalasang pinakikinggan sa pamahalaan maging sa hukuman ay mayayaman. Sa mga kasong kasangkot ang mayayaman, lagi silang nagwawagi at ang kawawang mahihirap ay umuwing luhaan. Ganito ang senaryo sa nobela lalo na sa mga elementong tauhan, tunggalian at balangkas gaya ng linyang, "Basta, alisan natin ng saka, tapos ang usapan.” Ang senaryong ito ay patunay na naganap ang pagmamaltrato ng mayaman sa maahirap o 
Alvarado, E.

magsasaka. Hindi na ito bagong senaryo maging sa tunay na buhay dahil napakaraming may-ari ng lupa na lalong lumalawak ang lupain dahil kinuha mula sa magsasaka kung nag-aalsa o ipinaglalaban ang karapatan. Malaking paglabag ito sa itinadhana ng Konstitusyon Artikulo III Selk. 8 na, "The right of the people, including those employed in the public and private sectors, to form unions, associations, or societies for purposes not contrary to law shall be abridged." Ang batas na ang nagsabi na karapatan ito ng mga manggagawa kaya walang karapatan ang may-ari ng lupa na kunin ang kanilang ani o lupa na walang "due process" o hindi pagsunod sa batas. Malaking paglabag ito sa karapatang pantao ng bawat magsasaka at manggagawa. Ang talahanayan 3 ay paglalarawan sa kawalan ng karapatang mamuhay ng payapa at masagana ng mga tao dulot ng pagpanig ng pamahalaan sa mayaman.

\section{Talahanayan 3}

Isyung Politikal

\begin{tabular}{lll}
\hline Mukha ng Buhay na Sinasagisag & Mga Elemento ng Nobela & \multicolumn{1}{c}{ Paglalarawan } \\
\hline Paglabag sa karapatang-pantao & Tauhan & $\begin{array}{l}\text { Walang kalayaan ang mga magsasaka na } \\
\text { makapagsalita } \\
\text { Pinaalis ang mgaiskuwater sa kanilang tahanan na } \\
\text { walang palugit. }\end{array}$ \\
& Tunggalian & $\begin{array}{l}\text { Hindi pinakikinggan ni Donya Leona ang mga } \\
\text { hinaing magsasaka. }\end{array}$ \\
& Balangkas & $\begin{array}{l}\text { Piniit sa kulungan sina Andres, Tasyo at Blas na } \\
\text { walang "due process }\end{array}$ \\
\hline
\end{tabular}

Batay sa talahanayan 3, ipinapakita lang na ang nobela ni Hernandez ay punong-puno ng suliranin sa larangang politikal. Kahit saang sulok ng bansa ay nakikita at nararanasan ito ng bawat tao. Ang pangunahing dahilan ay mahirap ang biktima at mayaman ang salarin. Ang kawalan ng karapatang-pantao ay dulot na rin ng kahinaang loob ng inaapi. Ika nga, walang mang-aapi kung walang magpapaapi. Tama, hindi mamayani ang kapangyarian ng pamahalaan kung may lakas ang tao na ipaglaban ang kanilang karapatan. Ang nobela ni Hernandez ay repleksyon ng mga pangyayaring panlipunan katulad ng pagkakulong na walang kalaban-laban, paghuli ng mga pulis na walang ebidensya at pagpataw ng desisyon ng korte na walang "due process." Ang mga nabanggit ay ipinapakita sa mga tauhan, tunggalian at balangkas.

Bawat Pilipino ay may karapatan, patunay ang nakasaad sa Social Justice and Human Rights ng Konstitusyon Artikulo XIII Sek.1 at 2 na, "The Congress shall give highest priority to the enactment of measures that protect and enhance the right of all people to human dignity, reduce social, economic, and political inequalities and remove cultural inequalities by equitably diffusing wealth and political power for common good." Maliwanag na may karapatang nakalaan sa bawat tao o magsasaka. Binibigyan ng sapat na proteksyon ang bawat isa upang magawa ang kanyang ninanais hanggat hindi ito nakalalabag sa karapatang-pantao. Sa akdang sinuri, lantarang ipinapamalas ang kawalan ng karapatan lalo na sa mga mahihirap. Masyadong taliwas ang mga pangyayari sa batas na nabanggit. Sukdulan ang pagmamaltrato ng mayayaman sa mahihirap katulad ng pamilya Grande laban samga kasama (magsasaka).

Sa kagustuhang masidlan at magkalaman ang kumakalam na sikmura, kayang gawin ang lahat upang makakain nang masarap ang pamilya. Nagpapadala na lang sa takbo ng panahon para lamang makatikim ng masarap na ulam ang pamilya. Sa kasong ito, nararaat bigyang panahon ang taong inakusahan na makapagsalita sa kanyang panig bago dakpin ng pulis. Malinaw sa senaryong ito na ginamit ng pulis ang kapangyarihan sa batas upang gawin ang mali. Ang ugnayang politikal ng mayaman sa alagad ng batas ay litaw na litaw sa nobela. Kung tutuusin, hindi naman ito pagnanakaw dahil kusa itong ibinigay ngunit ipinalabas na ninakaw. Maliit na bagay lang ito at hindi pa matitibag ang yaman ng mga Grande ngunit sukdulang sama ng mayaman para lang hindi maibsan ang kayamanan nito.

Ang paggamit ng kapangyarihan ng namumuno sa bayan ay isang paglabag sa kanyang panunungkulang maglingkod nang tapat sa mamamayan. Patunay ang pangyayaring kinasasangkutan ng alkalde ng Sampilong na sumang-ayon sa pamilyang Grande na paailisin sa kanilang mga barung-barong dahil maruming tingnan. Kahit 
pa man may ibinigay ito ng pamahalaan sa mga iskuwater ay bigla lamang ipinamukha sa kanila na hindi sila may-ari ng lupa. Malinaw lang na mas makapangyarihan ang pera sa lahat ng bagay sa mundo.

Ang pagdulog ng mga iskuwater sa hukuman upang ilaban ang kanilang karapatan ay hindi nagtagumpay. Nananaig ang pera ng mga Grande at hindi na makabali sa Tambakan ang mga tao. Ginamit ng pamilya Grande ang kapangyarihan para bilhin ang batas. Isang motibo na nilabag ang karapatan ng tao na mabuhay nang payapa. Samantalang sinasabing instrument ng kapayapaan ang pulis ngunit ginamit ang kanilang posisyon upang maisakatuparan ang balak ng maylupa. Iyan ay isa sa mga suliraning sinasalamin sa akdang sinuri, hitik sa batas at katarungan.

Ang katarungan ay tumutukoy sa karapatang ipapataw sa isang inosenteng taong nasasakdal at naipakulong ang tunay na salarin. Nagkakaroon lamang ng patas at pantay na pagpapasya kung dumadaan sa mahabang proseso at binibigyan ang bawat isa ng abogado upang maipalabas ang saloobin. Ang mga usaping nabanggit ay malinaw na nakapaloob sa nobela. Ang paggamit ng opisyal sa kanilang posisyon sa pamahalaan para magawa ang kanilang ninanais kahit pa may naapakang tao ay labag sa batas. Naghahatid ito ng suliranin at pagtutunggali ng mahirap at mayaman at higit sa lahat ito ang puno’tdulo ng lahat ng tauhan sa pakikipaglaban.

\section{Mga natuklasan}

Batay sa masusing pag-aaral, natuklasan na gumamit ang mga magsasaka ng matayutay na pahayag gaya ng pagtutulad, pagwawangis, pagmamalabis, at pagtatanong gayundin ang idyomatikong pahayag upang hindi lantarang maipahayag ang kanilang layunin sa pag-aalsa; lantad na lantad ang isyung panlipunan gaya kahirapan, pag-ibig, at makapangyarihan ang mayaman; at nagpabayad ang namumuno sa pamahalaan upang bilhin ang batas.

\section{Konklusyon}

Batay sa resulta ng pag-aaral, napatunayang ang nobelang Luha ng Buwaya ni Amado V. Hernandez ay gumamit ng matayutay na pahayag at lantad ang mga isyung panlipunan gaya ng kahirapan, pag-ibig, at makapangyarihan ang mayayaman at biktima ang mahihirap sa mga isyung politikal tulad ng paglabag sa karapatang-pantao at kawalan ng katarungan.

\subsection{Rekomendasyon}

Ang pag-aaral ay nagnanais na makatulong sa ikakaunlad pa ng panitikan sa pamamagitan ng pagsubaybay sa mga batas na may kaugnayan sa karapatang-pantao na nilabag sa nobelang ito upang maisatitik ang pagtadhana sa batas ng Pilipinas at mapapahalagahan ang panitikang sinuri sa pamamagitan ng pagdalumat sa ugnayan sa buhay ng may-akda sa kanyang obra.

\section{Mga sanggunian}

Arrogante, J. A., et al. (1983). Panitikang Filipino: Antolohiya. Quezon City: National Bookstore. Buensuceso, T. A., et al. (1997). Panitikang Filipino. España Blvd., Manila: UST Publishing House. Reyes, S. (1982). Nobelang Tagalog 1902-1975. Quezon City: Ateneo, UP. Salazar, L. A., et al. (1995). Panitikang Filipino. Quezon City: Katha Publishing Co., Inc. Santiago, L. Q., at Antonio L, F. (2007). Mga panitikan ng Pilipinas. Quezon City: C \& E Publishing, Inc. Yu, R, T. (2006). Kilates: Panunuring pampanitikan. Quezon City: UP Press 
Alvarado, E. 